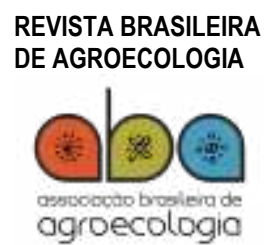

ISSN: 1980-9735

DOI: 10.33240/rba.v14i1.22873

Vol. 14 | No. $1 \mid$ p. $03-08$ | 2019

\title{
EFEITOS DE DIFERENTES CONCENTRAÇÕES DE RESÍDUO INDUSTRIAL DE SUPLEMENTO MINERAL PARA ANIMAL SOBRE O CRESCIMENTO DE PLANTAS DE GIRASSOL
}

Effects of different concentrations of industrial residue from animal mineral supplement on growth of sunflower plants

1 Graduanda em Engenharia Ambiental e Sanitária, Instituto Federal de Educação, Ciência e Tecnologia do Ceará, Campus Maracanaú; E-mails: mmoreiralais@gmail.com; mouralorenaf@gmail.com.

2 Mestranda do Programa de PósGraduação em Energias Renováveis, Instituto Federal de Educação, Ciência e Tecnologia do Ceará, Campus Maracanaú; E-mail:

fabianabraz13@hotmail.com.

3 Instituto Federal de Educação, Ciência e Tecnologia do Ceará, Campus Maracanaú; E-mails: roberto.consultorambiental10@gmail.com aragaofg@yahoo.com.br.

Recebido em:

28/11/2018

Aceito para publicação em: 02/12/2018

Correspondência para: aragaofg@yahoo.com.br
Laís Marques Moreira'; Lorena Ferreira Moura'; Fabiana Barbosa Bráz de Almeida²; Roberto Albuquerque Pontes Filho3 e Franklin Aragão Gondim ${ }^{3}$

\begin{abstract}
Neste trabalho avaliou-se o uso de diferentes concentrações de resíduo de suplemento animal (RSA) para a composição de substratos para o cultivo de plantas de girassol (Helianthus annuus L.) sobre o crescimento e teores de solutos orgânicos. O uso do RSA a 50\% ocasionou incrementos no número de folhas, área foliar, diâmetro do coleto e teor de $\mathrm{N}$-aminossolúveis das folhas, em comparação aos tratamentos areia e fertilizante comercial. Assim, o uso do RSA a 50\% da RN mostrou-se eficaz, podendo tornar-se uma alternativa viável e ambientalmente vantajosa.
\end{abstract}

Palavras-chave: Adubo mineral. Helianthus annuus L. Resíduo sólido industrial.

\section{RESUMO}

The study evaluated the use of different concentrations of animal supplement residue (ASR) to the composition of substrates for sunflower plants (Helianthus annuus L.), on growth and organic and inorganic solutes contents. The use of $50 \%$ ASR caused increases in the number of leaves, leaf area, stalk diameter and $\mathrm{N}$-aminosoluble content of leaves compared to sand and commercial fertilizer treatments. Thus, the use of ASR at $50 \%$ of the RN was effective and could become a feaseble and environmentally advantageous alternative.

Keywords: Mineral fertilizer. Helianthus annuus L. Industrial solid waste. 
A destinação final dos resíduos sólidos industriais (RSI) é motivo de grande preocupação dos órgãos ambientais. Este fato é resultado da intensa atividade industrial, bem como pela carência de locais adequados para o tratamento e acondicionamento dos resíduos. A disposição incorreta desses materiais é responsável por inúmeros problemas, tais como: poluição dos recursos naturais, proliferação de vetores transmissores de doenças, degradação da paisagem, mau cheiro, assoreamento de corpos d'água, dentre outros (JACOBI e BESEN, 2011).

Entretanto, a partir da Lei no $12.305 / 2010$, as empresas passaram a ser obrigadas a tomar medidas para atenuar a poluição ambiental, devendo buscar a gestão integrada e o gerenciamento ambientalmente correto dos resíduos sólidos (BRASIL, 2010a).

O reuso de RSI em solos agrícolas vem sendo visado como uma opção, devido a esses materiais geralmente possuírem propriedades de correção de acidez e grande potencial para fornecer nutrientes ao solo. Essa já é uma alternativa muito utilizada em países, como Estados Unidos, Holanda e Austrália (PIRES e MATTIAZZO, 2008). Nesse contexto, uma empresa do ramo de nutrição animal, situada em São Gonçalo do Amarante - Ceará, Brasil, gera, em média, 20 toneladas por mês de resíduos de suplemento animal por falhas ou irregularidades ocorridas durante o processo produtivo. Devido ao seu rigoroso controle de qualidade, esse material não conforme passa a ser classificado como resíduo de classe ll e é encaminhado ao Aterro Sanitário Metropolitano de Caucaia (ASMOC) - CE. Além de ocupar espaço no aterro sanitário, diminuindo sua vida útil, esse material contribui para a atração de insetos, aracnídeos e proliferação de bactérias. Apesar de ser um composto altamente rico em macro e micro minerais, apresenta, elevadas concentrações de $\mathrm{NaCl}$, substância que, em excesso, é prejudicial ao crescimento de diversas plantas.

A espécie utilizada nesta pesquisa, Helianthus annuus L., consiste em uma oleaginosa moderadamente tolerante à salinidade, mas que pode sofrer redução progressiva do crescimento conforme o aumento da concentração de sais (SILVA et al., 2017). No Brasil, o girassol se destaca por seu enorme potencial para a produção de energia renovável. Dentre seus usos, estão a produção de forragem alternativa, planta melífera, ornamental, produção de óleo para alimentação humana e animal, além de produção de biocombustível (FAO, 2013; GLOVATSKI e RAIHER, 2013; GOMES et al., 2015). Não há na literatura pesquisas que abordem o uso desse resíduo na composição de substratos, assim como na melhoria no crescimento e produção vegetal. O presente trabalho objetivou avaliar o uso de diferentes concentrações de resíduo de suplemento animal (RSA) para a composição de substratos para o cultivo de plantas de girassol (Helianthus annuus L.), avaliando os efeitos sobre o crescimento e teores de solutos orgânicos, bem como a verificação de viabilidade do uso desse resíduo como fertilizante.

O suplemento mineral para animais é uma combinação de macro e micro minerais e fontes proteicas, como farelos de milho e soja. Já o seu resíduo consiste em uma mistura de produtos avariados, varrições de fábrica e limpeza interna de equipamentos, os quais são coletados e acondicionados em container até serem destinados ao Aterro Sanitário Metropolitano Oeste de Caucaia - CE. Esse resíduo é insolúvel, apresenta aspecto pulverulento, com diâmetro máximo característico de $1,2 \mathrm{~mm}$, módulo de finura 0,88 , determinados a partir de ensaios conforme metodologia da NBR $248 / 2003$, e densidade em torno de 2,0 a $2,7 \mathrm{~g} / \mathrm{cm}^{3}, \mathrm{pH} \mathrm{7,5}$, verificados por meio da Ficha de Informações de Segurança de Produtos Químicos - FISPQ, documento normalizado pela NBR 14.725/2001, fornecida pela empresa.

Foram doadas pela empresa, duas toneladas de resíduo sólido do suplemento animal e, em seguida, procederam-se as análises químicas do resíduo, pelo Laboratório de Solos da Universidade Federal do Ceará, para conhecimento da composição do material e posterior formulação dos substratos para cultivo de plantas de girassol.

O experimento foi conduzido em casa de vegetação pertencente ao Laboratório de Bioquímica e Fisiologia Vegetal do Instituto Federal de Educação, Ciências e Tecnologia do Ceará - Campus Maracanaú, Ceará, Brasil. Os valores médios de temperatura e umidade relativa do ar durante o dia dentro da casa de vegetação foram, respectivamente, $33,3{ }^{\circ} \mathrm{C}$ e $54 \%$ obtidos por meio da medição de um termohigrógrafo digital. 
Com o objetivo de remover completamente a umidade do material, colocou-se uma amostra do resíduo em estufa com circulação forçada de ar durante quatro dias, a $60{ }^{\circ} \mathrm{C}$ até atingir massa constante. A quantidade de resíduo sólido industrial no cultivo de girassol foi mensurada conforme a recomendação de plantio de $80 \mathrm{~kg}$ de nitrogênio por hectare (EMBRAPA, 1983).

Para a montagem do experimento foram utilizados 60 baldes plásticos com capacidade de $5 \mathrm{~L}$, perfurados na extremidade inferior. A irrigação realizada durante a condução do experimento foi diária e de forma manual, visando manter o teor de água próximo à capacidade de campo do solo. As sementes de girassol, cultivar BRS 323, foram doadas pela Embrapa Algodão e semeadas diretamente nos vasos contendo os diferentes tratamentos, a uma profundidade aproximada de $3 \mathrm{~cm}$. A areia utilizada no experimento é classificada como tipo grossa, com diâmetro dos grãos entre 0,6 e $2 \mathrm{~mm}$, a qual foi obtida comercialmente.

Foram utilizados os seguintes tratamentos: areia; areia + NPK + Micro FTE BR 12 (adubo comercial a $100 \%$ da Recomendação de Nitrogênio - RN); areia + RSA a 50\% da RN; areia + RSA a 100\% da RN; areia + RSA a $150 \%$ da RN; e areia + RSA a $200 \%$ da RN.

No tratamento utilizando adubo comercial, o NPK serviu como fonte de macronutrientes, apresentando partes iguais para os três elementos, na proporção 10-10-10. É importante ressaltar que, apesar de o nitrogênio $(\mathrm{N})$, fósforo $(\mathrm{P})$ e potássio $(\mathrm{K})$ estarem em maiores proporções nesse composto, quantidades discretas de cálcio ( $\mathrm{Ca})$, magnésio $(\mathrm{Mg})$ e enxofre (S) são, também, verificadas. Já o Micro FTE BR 12, que foi incorporado ao NPK, consiste em um coquetel de micronutrientes para solo, com garantias mínimas de Molibdênio (Mo) - 0,1\%, Boro (B) - 1,8\%, Cobre (Cu) - 0,8\%, Manganês (Mn) - 2\% e Zinco $(Z n)-7 \%$.

Aos 15, 22, 29 e 33 dias após a semeadura (DAS), realizaram-se as avaliações da altura da parte aérea, diâmetro do coleto e número de folhas. As avaliações da altura da parte aérea foram realizadas com o auxílio de uma régua graduada em centímetros, considerando a altura da base da planta (superfície do substrato) até a extremidade da folha mais estendida; o diâmetro do coleto (caule), medido próximo da superfície do substrato, foi avaliado com o auxílio de um paquímetro digital e o número de folhas foi contado manualmente.

Os teores de proteínas solúveis foram determinados de acordo com o método descrito por Bradford (1976); os de carboidratos solúveis, de acordo com Dubois et al. (1956); os de Naminossolúveis, pelo método de Yemm e Cocking (1955); e os de prolina, conforme Bates et al. (1973).

O experimento foi conduzido em delineamento inteiramente casualizado, com 6 tratamentos e 10 repetições com 3 plântulas. Para o tratamento dos dados, utilizaram-se os programas Microsoft Office Excel 2013; SISVAR $^{\circledR}$ para análises estatísticas e o SigmaPlot ${ }^{\circledR} 11.0$ para gerar gráficos. Para as variáveis, número de folhas, diâmetro dos caules e altura da parte aérea, os dados foram submetidos à análise de variância (ANOVA) e regressão polinomial. Já para os dados de teores de solutos orgânicos, ANOVA e as médias comparadas pelo teste de Tukey $(P \leq 0,05)$.

Dos substratos propostos, somente três possibilitaram a germinação das sementes de girassol: o resíduo de suplemento animal (RSA) a 0\% (somente areia); RSA a 50\% da recomendação de nitrogênio (RN) e fertilizante comercial (NPK + Micro FTE BR12) a 100\% da RN. Devido ao seu aspecto pulverulento, o RSA é altamente higroscópico. Dessa forma, observou-se que solos contendo maiores concentrações de resíduo de suplemento animal apresentavam-se mais compactados, com espaços vazios mais preenchidos. Essa característica do RSA pode ter dificultado a penetração de oxigênio, favorecendo condições de hipóxia e, consequentemente, a não germinação das plântulas.

Em relação à altura das plantas (Figura 1A), aos 33 DAS, o tratamento com NPK obteve a melhor média comparada às dos outros tratamentos, sendo o modelo de regressão linear, aos quais melhor se ajustaram com coeficientes de ajuste $R=0,9935$. $O$ resultado foi de encontro àqueles encontrados por Costa Filho et al. (2017).

Na Figura 1B, relacionada ao número de folhas (NF), as plantas suplementadas com RSA obtiveram um incremento expressivo a partir do 22을, superando, aos 33 DAS, em 129 e 45,5\% os tratamentos RSA 0 e NPK, sendo o modelo de regressão polinomial, aos quais melhor se ajustaram com 
coeficientes de ajuste $R=0,9999$. Resultados semelhantes foram encontrados por Nunes et al. (2017) e Nascimento et al. (2006). Diferentemente dos resultados anteriores, Costa Filho et al. (2017) não observaram diferença significativa no tratamento com resíduo da carcinicultura a 50\% comparado ao tratamento controle (areia).

O diâmetro dos caules (Figura $1 \mathrm{C}$ ) seguiu um comportamento semelhante ao do NF, mostrandose, aos 33 DAS, o tratamento RSA 50 cerca de 41 e $16 \%$ superior aos tratamentos com RSA 0 e NPK, respectivamente, sendo o modelo de regressão polinomial, aos quais melhor se ajustaram com coeficientes de ajuste $R=0,9948$. Esses resultados corroboram com os encontrados por Melo et al. (2014) ao estudar os aspectos biométricos da cultura do girassol fertilizados com resíduo lácteo, assim como Silva et al. (2014), utilizando fibra de coco como substrato. Diâmetros maiores de caules são preferíveis na cultura do girassol, uma vez que essa espécie apresenta em sua fase reprodutiva uma inflorescência do tipo capítulo, com elevada massa, podendo provocar acamamento em plantas que apresentam caules com reduzidos diâmetros (BISCARO et al., 2008).

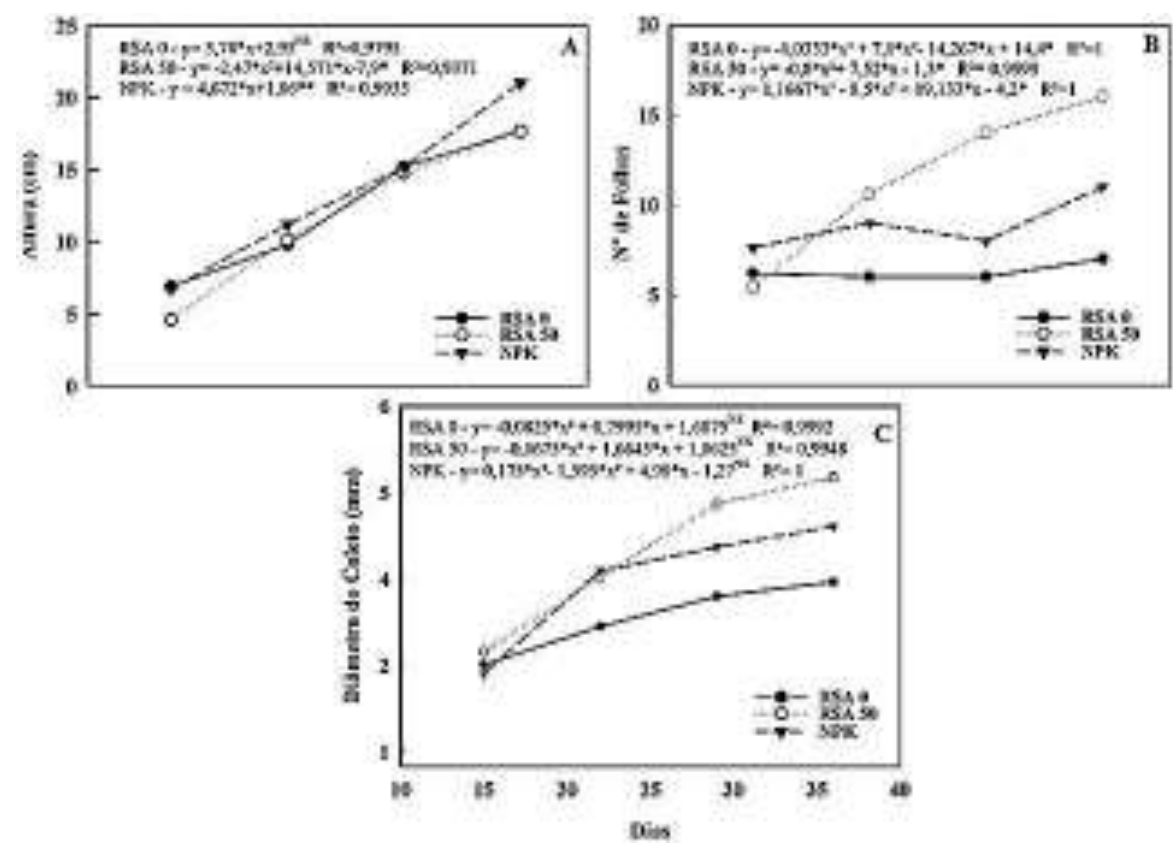

Figura 1. Altura da parte aérea (A), número de folhas (B) e Diâmetro do coleto (C) de plântulas de girassol cultivadas em diferentes concentrações de resíduo de suplemento animal ou NPK. Os valores representam as médias de 5 repetições \pm os erros padrão. *Significativo a 0,01 de probabilidade; ** Significativo a 0,05 de probabilidade; NS Não Significativo.

Na literatura não há relatos referentes ao uso de resíduos sólidos de suplemento animal (RSA) sobre o crescimento de plantas de girassol. Sugere-se, então, que a aplicação de RSA ao substrato tenha ocasionado aumento no diâmetro do coleto e número de folhas das plantas devido à melhoria de propriedades físicas e químicas do solo quando aplicado em pequenas concentrações (RSA 50). Além disso, por se tratar de um resíduo com aspecto sólido, acredita-se que os efeitos de uma possível lixiviação também tenham sido reduzidos no substrato, possibilitando um estoque de nutrientes por um período maior para a planta.

A Figura 2 mostra os teores de solutos orgânicos das folhas e raízes, aos 33 DAS, em plântulas de girassol. Com relação às proteínas solúveis das folhas (Figura $2 A$ ), não foram observadas diferenças significativas entre os tratamentos RSA 0 e RSA 50. Contudo, esses diferiram significativamente do tratamento com NPK, sendo esse superior em 35 e $26 \%$, respectivamente.

Para carboidratos solúveis das folhas (Figura 2B), as plantas submetidas ao tratamento RSA 50 e NPK não diferiram entre si e foram, em média, $27 \%$ superiores ao tratamento areia. Esse resultado difere do obtido por Braga et al. (2017), no qual as maiores concentrações de carboidratos ocorreram nos tratamentos suplementados com os resíduos da carcinicultura. Para prolina das folhas (Figura 2C), não houve diferença significativa entre os tratamentos. Por fim, os $\mathrm{N}$-aminossolúveis nas folhas (Figura 
2D) foram maiores no tratamento com o resíduo de suplemento animal, superiores em 19 e $11 \%$, quando comparados aos tratamentos RSA 0 e NPK, respectivamente.

Com relação aos teores de solutos orgânicos nas raízes, observou-se que, para os teores de proteínas solúveis (Figura 2E), o tratamento com NPK apresentou maior percentual, superior em 17 e $10 \%$ comparado ao RSA 50 e RSA 0, respectivamente. Para carboidratos solúveis nas raízes (Figura 2F), não houve diferenças significativas entre os três tratamentos, semelhante aos resultados obtidos por Braga et al. (2017), ao utilizar resíduos da carcinicultura como fertilizante em plantas de girassol. Já para a prolina (Figura 2G), observou-se que os tratamentos RSA 0 e RSA 50 foram semelhantes e significativamente inferiores aos obtidos pelo tratamento com NPK, em 68 e 60\%, respectivamente. Por fim, com relação aos $\mathrm{N}$-aminossolúveis (Figura $2 \mathrm{H}$ ), os tratamentos com resíduo sólido industrial e composto comercial não diferiram entre si e foram, em média, $73 \%$ superiores ao tratamento areia.

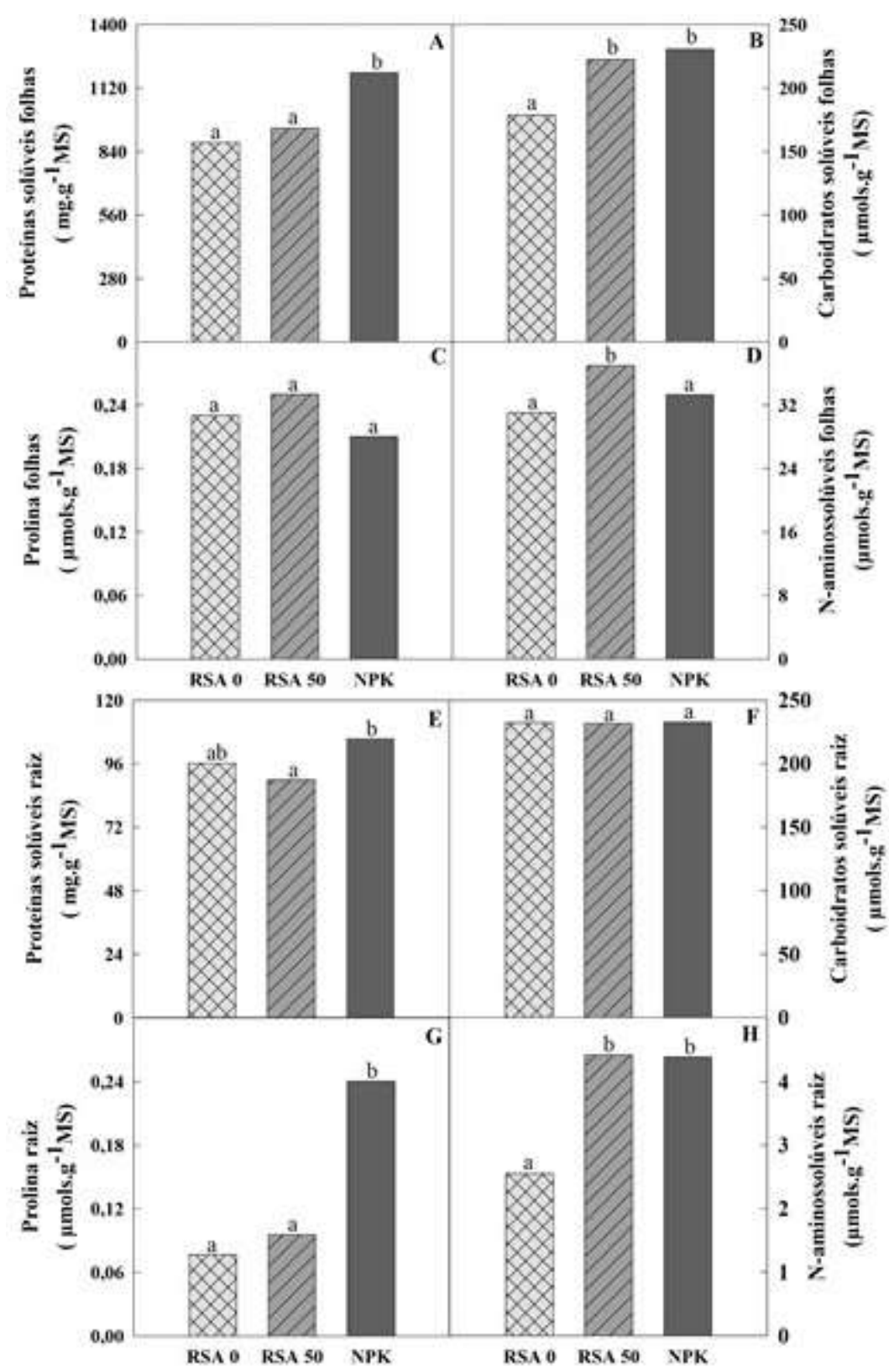

Figura 2. Proteínas solúveis das folhas (A), Carboidratos solúveis das folhas (B), Prolina das folhas (C), N-aminossolúveis das folhas (D), Proteínas solúveis das raízes (E), Carboidratos solúveis das raízes (F), Prolina das raízes (G) e N-aminossolúveis das raízes (H) de plantas de girassol em substratos contendo Resíduo de suplemento animal (RSA) a 0, RSA 50 (50\% da recomendação de nitrogênio- RN) e NPK a $100 \%$ da RN aos 33 dias após semeadura. Diferentes letras indicam diferenças significativas entre os tratamentos de acordo com o Teste de Tukey $(P \leq 0,05)$. 
Nas condições experimentais empregadas, a aplicação de resíduo de suplemento animal a 50\% da recomendação de nitrogênio para a cultura promoveu os incrementos nas variáveis número de folhas, diâmetro do coleto e $\mathrm{N}$-aminossolúveis das folhas, em comparação aos tratamentos areia e fertilizante comercial (NPK).

Dessa forma, o uso do RSA é viável e eficaz em concentrações de/com até $50 \%$ da recomendação de nitrogênio $(80 \mathrm{~kg} \mathrm{~N}$. ha-1), podendo tornar-se uma alternativa como fertilizante. No entanto, são necessários estudos adicionais.

\section{Referências}

ASSOCIAÇÃO BRASILEIRA DE NORMAS TÉCNICAS. NBR 248: Agregados- Determinação da composição granulométrica. Rio de Janeiro. 2003.

ASSOCIAÇÃO BRASILEIRA DE NORMAS TÉCNICAS. Ficha de informações de segurança de produtos químicos FISPQ. Rio de Janeiro. 2001.

BATES, L.; et al. Rapid determination of free proline for water-stress studies. Plant and Soil. 1973. 39, 205-207.

BISCARO, G. A.; et al. Adubação nitrogenada em cobertura no girassol irrigado nas condições de CassilândiaMS. Ciência e Agrotecnologia, p. 1366-1373, 2008.

BRADFORD, M. M. A rapid and sensitive method for the quantification of microgram quantities of protein utilizing the principle of protein-dye binding. Analytical Biochemistry, v. 72, p. 246-254, 1976.

BRAGA, B. B.; et al. Resíduo sólido de carcinicultura diminui os efeitos deletérios do estresse hídrico em plantas de girassol. Revista Brasileira de Agroecologia, v. 12, n. 3, 2017.

BRASIL. Política nacional de resíduos sólidos. Lei №. 12.305/2010. Brasília, 2010a.

COSTA FILHO, F. O. H.; et al. Effects of Different Concentrations of Organic Waste on Selected Traits of Individuals Capsicum Chinense Jacq. Journal of Plant Studies, v. 6, n. 1, p. 76, 2017.

DUBOIS, M.; et al. Colorimetric method for determination of sugars and related substances. Analytical chemistry, v. 28, n. 3, pp.350-356, 1956.

EMPRESA BRASILEIRA DE PESQUISA AGROPECUÁRIA - EMBRAPA. Centro Nacional de Pesquisa de Soja Londrina PR. Indicações técnicas para o cultivo do girassol. Londrina, 1983.

FOOD AND AGRICULTURE ORGANIZATION - FAO. World Food and Agricultural. Rome, 2013.

GLOVATSKI; T. G. G.; RAIHER, A. P. A oferta de matérias primas (oleaginosas) do biodiesel no Brasil e seus determinantes: uma análise dos anos de 1991 a 2010. Estudo \& Debate, v. 20, p. 07-32, 2013.

GOMES, K. R.; et al. Irrigação com água salina na cultura do girassol (Helianthus annuus L.) em solo com biofertilizante bovino. Irriga, v. 20, p. 680-693, 2015.

JACOBI, P. R.; BESEN, G. R. Gestão de resíduos sólidos em São Paulo: desafios da sustentabilidade. Estudos Avançados, São Paulo, v. 25, n. 71, p. 135-158, 2011.

MELO, J. P. R. de; et al. Aspectos Biométricos da Cultura do Girassol Fertilizados com Resíduo Lácteo no Agreste Pernambucano. Global Science And Technology, [s.I.], v. 7, n. 3, p.53-57,2014. Global Science and Technology.

NASCIMENTO, M. B. H.; et al. Uso de biossólido e de água residuária no crescimento e desenvolvimento da mamona. Revista Brasileira de Oleaginosas e Fibrosas, v. 10, n. 1-2, 2006.

NUNES, F. H.; et al. Crescimento foliar e atividades das enzimas antioxidativas em plântulas de girassol suplementadas com percolado de aterro sanitário e submetidas a estresse hídrico. Ambiente \& Água - An Interdisciplinary Journal of Applied Science, v. 12, n. 1, p. 71-86, 2017.

PIRES, A. M. M.; MATTIAZZO, M. E. Avaliação da viabilidade do uso de resíduos na agricultura. Embrapa Meio Ambiente. Circular técnica. 2008.

SILVA, R. de C. B. da; et al. Emergência de sementes de girassol (Helianthus annuus) sob estresse salino. Revista Semiárido de Visu, Petrolina, v. 5, n. 2, p. 80-87, 2017.

SILVA, V. F. da; et al. Cultivo de girassol em variedades de substratos. Revista Monografias Ambientais, v. 13, n. 4, p. 3453-3459, 2014.

YEMM, E. W.; COCKING, E. C. The determination of aminoacids with ninhydrin. Analyst, v. 80, p. 209-213, 1955. 